\title{
Versatility and "flap efficiency" of pedicled perforator flaps in lower extremity reconstruction
}

DOI:

10.1016/j.bjps.2016.09.028

\section{Document Version}

Accepted author manuscript

Link to publication record in Manchester Research Explorer

\section{Citation for published version (APA):}

Wong, J. K. F., Deek, N., Hsu, C-C., Chen, H-Y., Lin, C-H., \& Lin, C-H. (2017). Versatility and "flap efficiency" of pedicled perforator flaps in lower extremity reconstruction. Journal of plastic, reconstructive \& aesthetic surgery: JPRAS, 70(1), 67-77. https://doi.org/10.1016/j.bjps.2016.09.028

\section{Published in:}

Journal of plastic, reconstructive \& aesthetic surgery : JPRAS

\section{Citing this paper}

Please note that where the full-text provided on Manchester Research Explorer is the Author Accepted Manuscript or Proof version this may differ from the final Published version. If citing, it is advised that you check and use the publisher's definitive version.

\section{General rights}

Copyright and moral rights for the publications made accessible in the Research Explorer are retained by the authors and/or other copyright owners and it is a condition of accessing publications that users recognise and abide by the legal requirements associated with these rights.

\section{Takedown policy}

If you believe that this document breaches copyright please refer to the University of Manchester's Takedown Procedures [http://man.ac.uk/04Y6Bo] or contact uml.scholarlycommunications@manchester.ac.uk providing relevant details, so we can investigate your claim.

\section{OPEN ACCESS}




\title{
Versatility and "flap efficiency" of pedicled perforator flaps in lower extremity reconstruction
}

\author{
Jason K.F. Wong ${ }^{\text {a,b }}$, Nidal Deek ${ }^{a}$, Chung-Chen Hsu ${ }^{a}$, \\ Hsin-Yu Chen ${ }^{a}$, Chih-Hung Lin ${ }^{a}$, Cheng-Hung Lin ${ }^{a, c, *}$
}

\author{
a Department of Plastic and Reconstructive Surgery, Chang Gung Memorial Hospital, \\ Chang Gung University, College of Medicine, Taipei, Taiwan \\ b Plastic Surgery Research, Institute of Inflammation and Repair, University of Manchester, \\ Manchester, UK \\ c Center for Vascularized Composite Allotransplantation, Department of Plastic and Reconstructive \\ Surgery, Chang Gung Memorial Hospital, Taoyuan, Taiwan
}

Received 7 May 2016; accepted 26 September 2016

\section{KEYWORDS \\ Pedicled perforator flap; Anterolateral thigh flap; Medial sural artery perforator flap; Peroneal artery perforator flap; Posterior tibial artery perforator flap; Defect}

\begin{abstract}
Summary Background: The use of pedicled perforator flaps provides an alternative to free tissue transfer for lower limb reconstruction. We use computer-aided image analysis to investigate the versatility of pedicled perforator flaps for the reconstruction of lower limb defects.

Patients and methods: Between April 2007 and April 2011, a case series of 61 patients with wounds of the lower extremity from knee to ankle were reconstructed with pedicled perforator flaps. We performed 16 pedicled reverse-flow anterolateral thigh (RF-ALT) flaps, 8 pedicled medial sural artery perforator (MSAP) flaps, 26 pedicled peroneal artery perforator (PAP) flaps, and 11 pedicled posterior tibial artery perforator (PTAP) flaps. Digital planimetry of defects covered was analyzed and the "efficiency" of each flap was calculated, which allowed the assessment of the merits of each flap in the management of lower limb defects.

Results: Flaps healed primarily in $82 \%$ of cases $(50 / 61)$. Approximately $50 \%$ of the secondary donor sites required skin grafting. Complications requiring secondary surgery occurred in $18 \%(11 / 61)$ of the cases. Six required secondary skin grafting $(10 \%)$. One RF-ALT flap was converted into a free flap, one PAP required arterial supercharging, and three pedicled RF-ALT flaps required venous supercharging. Image analysis showed that these pedicled perforator flaps could cover $75 \%$ of the surface area of the lower leg. The higher length of perforator allowed for greater "flap efficiency" and better versatility of tissue cover.
\end{abstract}

\footnotetext{
* Corresponding author. Division of Trauma and Emergency Surgery, Department of Plastic and Reconstructive Surgery, Chang Gung Memorial Hospital, Chang Gung University, 5, Fu-Hsing St. Kuei-Shan, Taoyuan, Taiwan. Fax: +886 33289582.

E-mail address: lukechlin@gmail.com (C.-H. Lin).
} 
Conclusion: Image analysis can be used as a modality to assess the versatility of individual flaps in the reconstruction of lower limb defects.

(C) 2016 British Association of Plastic, Reconstructive and Aesthetic Surgeons. Published by Elsevier Ltd. All rights reserved.

\section{Introduction}

The technique of perforator dissection is a skill attributed to raising the modern free flap. ${ }^{1,2}$ This trend for intramuscular dissection of the perforator to provide extra pedicle length is gaining popularity as it allows for an increase in the versatility of local reconstructions. ${ }^{3}$ Flaps based on perforators aim to preserve the muscle function they pass through, and gain valuable pedicle length, hence maintaining the normal functional anatomy. ${ }^{4-6}$

This technique is also valuable when recipient vessels are diseased or where microsurgical reconstruction is considered too "risky," like in elderly patients or those who have significant comorbidities. It is a natural evolution of the locoregional flap reconstruction with the added refinement and confidence offered by visualization of the vascular anatomy. ${ }^{7}$ With flaps being close to the site of the defect, pedicled perforator flaps (PPFs) can potentially perform under regional block ${ }^{8}$ and reduce the need to transfer to specialized centers for postoperative microsurgical monitoring and care. In addition, they are less bulky, and are thought to have less associated risk than free flaps, as microsurgical anastomosis is not required. ${ }^{9}$ The use of PPFs also offer a comparable, "like for like" tissue type for reconstruction. However, perforator dissection is not universally practiced by all reconstructive surgeons. $^{10}$

Our hypothesis was that using four different PPFs we could reliably reconstruct most defects from the knee to the ankle and we sought out to determine how well each flap covered a range of lower limb defects.

Using image analysis software, we evaluated the limits of use of lower limb PPFs based on four frequently used perforator flaps of the lower leg. The objective was to show the relative limitations of cover and "flap efficiency" of the different flaps in order to understand which situations best suit their use.

\section{Patients and methods}

A retrospective case cohort study was performed on all lower extremity PPFs performed between April 2007 and April 2011 at the Chang Gung Memorial Hospital using standardized perforator flap nomenclature described by Saint-Cyr. ${ }^{11}$ Patients with consecutive lower limb injury or soft tissue defects who were felt to have low energy injuries and hence could be reconstructed by PPFs were included in this study, whereas those judged best managed by direct closure, skin graft, or free flap reconstruction were excluded. All cases were followed up until all wounds had healed. No cases were lost to follow up.
Data were collected on each flap group consisting of etiology, wound site and size, flap dimensions, advancement, rotation, donor site management, complications, and outcomes.

\section{Calculation of "flap efficiency"}

Multiple standardized photographs were taken, using a Canon DSLR camera, of the wound defect, the flap raised and flap at inset, from at least two different angles, with a single ruler scale and mapped onto a digital template using bony landmarks on a calibrated pixel mapping program on ImageJ Software. ${ }^{12}$ Digital planimetry measurements were calculated after all calibrated images were taken (Supplement Figure 1). The precise area of defect, area of flap raised, area of flap inset, angle of rotation, and distance of flap advancement were measured using the measurement features in the software program. For the purposes of quantification, the lower limb surface area was defined as the level from the superior aspect of the patella to the forefoot excluding the toes and sole. The surface area was measured in $\mathrm{cm}^{2}$ ( \pm standard error of mean).

The combined coverage of each flap according to the four types was mapped onto a surface area template and the percentage cover was calculated (Supplement Figure 2). Ratios were defined between size of defect to size of flap and size of flap to size of inset. Differences were sought between each perforator flap and analyzed for significance $(p<0.05)$ using analysis of variance (ANOVA) and post hoc Dunnett's C test. The "flap efficiency" was calculated based on the degree of defect covered in relation to the flap size (surface area of defect requiring cover/ surface area of flap raised $\times 100 \%$ ) with the higher value indicating higher efficiency. ${ }^{13}$

\section{Results}

A total of 61 patients (18 females and 43 males) with lower limb wounds were reconstructed using PPFs. The mean age of the patients was 48 years (4-88 years). Fifty defects were caused by trauma, four by burn injury, four by tumor excision, two by infection, and one by venous ulceration. Overall, the flaps used in this series were able to cover $75 \%$ of the lower limb surface area (Figure 1).

Sixteen pedicled reverse-flow antero-lateral thigh (RFALT) flaps were raised with dimensions ranging from $12 \times 6$ to $27 \times 12 \mathrm{~cm}$ (Figure 2). Donor site was closed primarily in 13 cases, with shoelace technique in two cases, and one by split thickness skin graft (STSG). Fascia lata for patellar tendon repair was included in three cases. Venous congestion was noted in eight cases, three of which were 


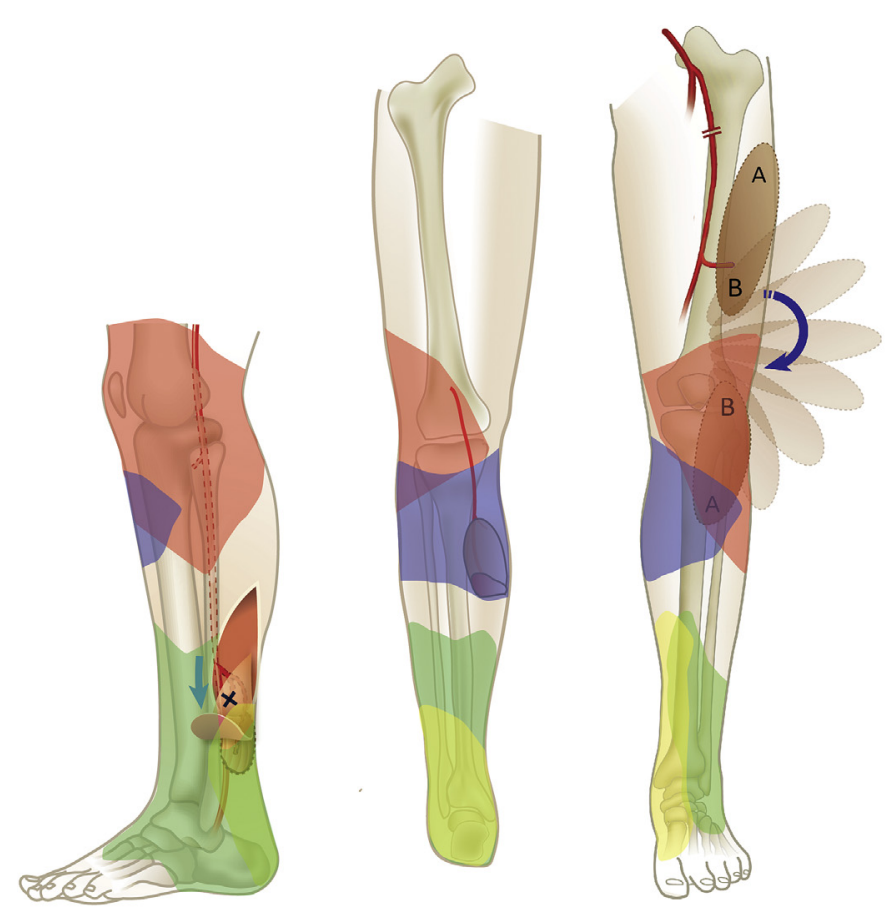

Pedicled Perforator

Area of cover

\section{RF-ALT $\quad 26 \%$ \\ MSAP $15 \%$ \\ PTAP $19 \%$ \\ PAP $\quad 22 \%$}

Not covered $\quad 25 \%$

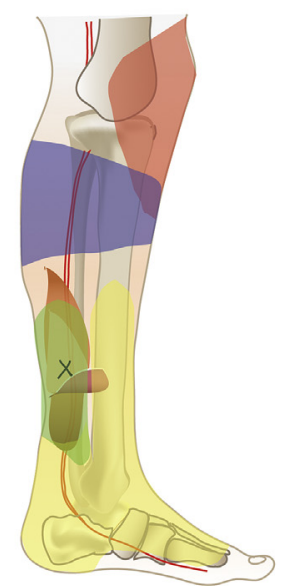

Figure 1 Location of lower limb defects covered by pedicled perforator flaps in our series. Majority of areas have been covered except the area joining the proximal and middle third of the lower leg.

salvaged with venous supercharging with the long saphenous vein. Two that were not venous supercharged underwent partial flap necrosis and one had a minor wound infection. All other RF-ALT flaps survived without complication. Through surface mapping of the injuries sustained, the defects covered by this flap accounted for $26 \%$ surface area of the lower limb (Figure 1).

Eight pedicled medial sural artery perforator (MSAP) flaps were raised with dimensions ranging between $10 \times 6$ and $15 \times 10 \mathrm{~cm}$ (Figure 3 ). Donor site was closed primarily in three cases, by shoelace technique in one case, and by STSG in four cases. All flaps healed without any complications (Table 1). The defects covered by this flap accounted for $15 \%$ surface area of the lower limb (Figure 1).

A total of 26 pedicled peroneal artery perforator (PAP) flaps were raised with dimensions ranging from $7.5 \times 3$ to $23 \times 8 \mathrm{~cm}$ (Figure 4): 16 flaps were propeller, five were peninsular, two were advancement, two were proximally based island, and one was a distally based island flap. Donor site was closed primarily in five cases, by shoelace in one case, by skin grafting in 20 cases. Venous congestion occurred in five cases that had a propeller design, resulting in partial tip necrosis. These required secondary STSG in two while the rest healed by secondary intention. One case of arterial insufficiency was observed with advancement of a PAP flap that was salvaged by additional perforator supercharging with no subsequent complications (Table 1). The defects covered by this flap accounted for $22 \%$ surface area of the lower limb (Figure 1).

Eleven pedicled posterior tibial artery perforator (PTAP) flaps were raised with a surface area ranging from $12 \times 3$ to $24 \times 5 \mathrm{~cm}$ (Figure 5): eight flaps were propeller, two were peninsular, and one was distally based island flap. The donor site was closed primarily in six cases and by STSG in five cases. Seven flaps had uneventful healing course while four had distal tip necrosis that required STSG to heal (Table 1). The defects covered by this flap accounted for 19\% surface area of the lower limb (Figure 1).

The average size of the defect requiring coverage was 68 (11) $\mathrm{cm}^{2}$ for the RF-ALT flap, $39.5(6.4) \mathrm{cm}^{2}$ for MSAP flap, $19(3.4) \mathrm{cm}^{2}$ for the PAP flap, and $20(6.7) \mathrm{cm}^{2}$ for the PTAP flap (Figure 6A).

Mean size of flap was $117(18.7) \mathrm{cm}^{2}$ for the RF-ALT flap, $56.5(6.8) \mathrm{cm}^{2}$ for MSAP flap, $65(9.8) \mathrm{cm}^{2}$ for the PAP flap, and $68(12.5) \mathrm{cm}^{2}$ for the PTAP flap. Inset saw a slight reduction in size of all flaps (Figure $6 \mathrm{~B}$ and $\mathrm{C}$ ).

The mean skin graft required for the donor site was 10.4 (10.4) $\mathrm{cm}^{2}$ for the RF-ALT flap, 7 (3.4) $\mathrm{cm}^{2}$ for MSAP flap, $22.5(6.3) \mathrm{cm}^{2}$ for PAP flap, and $26(15) \mathrm{cm}^{2}$ for PTAP flap (Figure 6D).

Advancement of the flaps was short for the PAP and PTAP managing on average $1.3(0-7.7)$ and $2 \mathrm{~cm} \mathrm{(0-3.7),}$ respectively. Advancement for the MSAP flap and RALT flap was significantly higher $(p>0.05)$ at $7.4(3.5-11.2)$ and $19.6 \mathrm{~cm}$ (9-29), respectively (Figure 7A).

All flaps offered a good range of rotational freedom with the RF-ALT flap averaging $129^{\circ}$, MSAP averaging $80^{\circ}$, PAP averaging $94^{\circ}$, and PTAP averaging $62^{\circ}$ (Figure 7B).

The flap size to flap cover ratio found most flaps maintained between $72 \%$ and $95 \%$ of their original size at inset (Figure 8A).

In terms of "flap efficiency," the least efficient was the PTAP (31.4\%), followed by PAP (33.2\%) then RALT flap (61\%), and the most efficient was the MSAP flap (70\%). The MSAP and RALT flaps were significantly more efficient than the other flaps $(p>0.05)$ (Figure $8 \mathrm{~B})$.

The flap characteristics and efficiency were summarized in Table 2. 


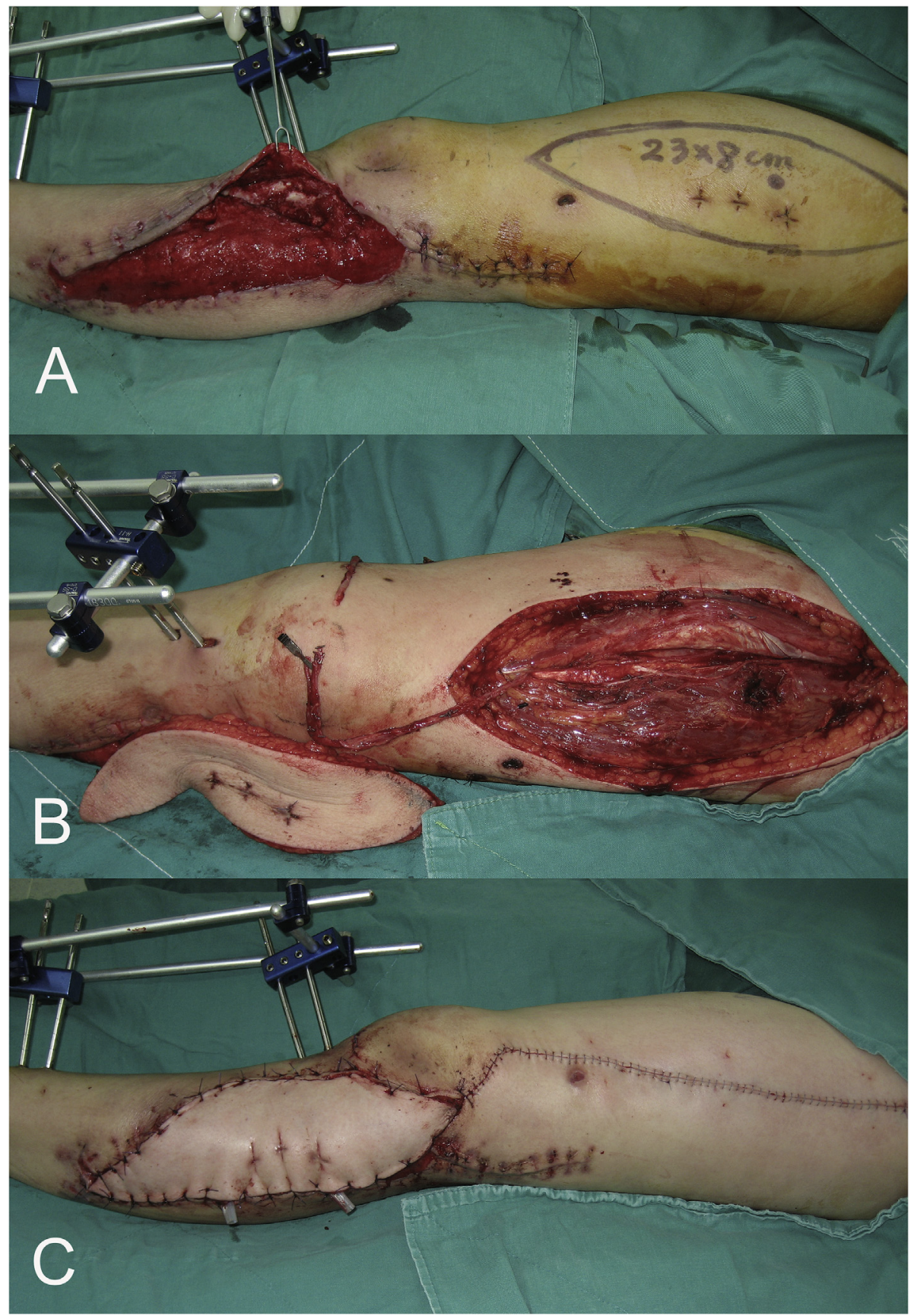

Figure 2 A large lateral knee and proximal lower leg injury (A) reconstructed with a RF-ALT flap with "venous supercharging" to provide good lower limb coverage $(B)$ and primary wound closure of the donor site $(C)$.

\section{Discussion}

PPFs have revolutionized lower limb reconstruction as they liberate flap design from the constraints of width-to-length ratio, provide flexibility in design, and decrease donor site morbidity. The technique of perforator dissection is required to liberate the pedicle, and provide the flap with a higher range of freedom to cover the adjacent defect well. ${ }^{11}$ In our series, PPFs have provided primary healing in $82 \%$ of our cases (Supplement Figure 3) with six cases requiring secondary skin grafting for unhealed areas and additional microsurgery being required to salvage five cases.
Hence, the perception that these forms of reconstruction have less associated risks and do not require microsurgical training is questionable. A recent systematic review has shown that the overall failure rate and complication rate were similar to that of free tissue transfer, whereas partial necrosis of PPFs was more prevalent at 7\% compared with $2.7 \%$ in free flaps. ${ }^{14}$ It is important to realize the limitations of these flaps in the setting of lower limb trauma, they do not strictly represent the surgical panacea. In our practice, we make a balanced assessment based on the extent of trauma against bringing in free tissue on a patient-bypatient basis. Certainly, advantages include lesser surgical 


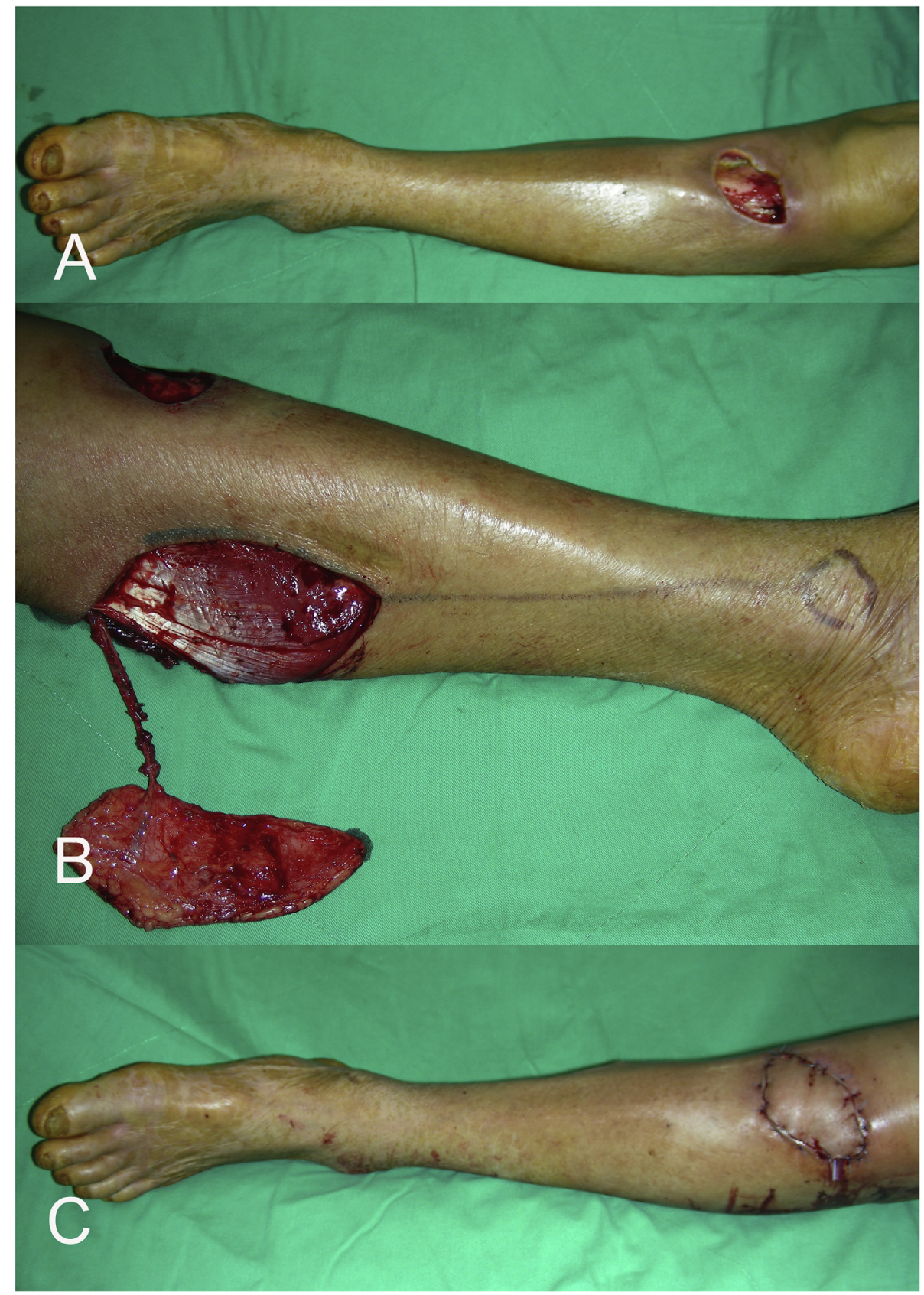

Figure 3 A small prepatellar defect (A) reconstructed with pedicled MSAP flap (B) providing good skin match and cover (C).

time and like for like tissue. The main trunk of the supplying vessel is not disturbed and therefore flow to the distal limb is preserved during pedicled perforator flap transfers. But from our series, it is clear that microsurgical availability is important. Each flap can cover defects around the lower leg ranging from $15 \%$ to $26 \%$ of the surface area. The MSAP and ALT flaps provide cover around the knee, whereas the PAP and PTAP cover around the distal tibia and ankle. This leaves a watershed area around the proximal and middle third of the tibia that was not reconstructed by these four flaps. In our experience, free tissue transfer or local hemisoleus muscle flaps were preferred in this region. ${ }^{15}$

Perforator flaps can be raised at many anatomical sites where a decent perforator exists ${ }^{7}$ and can be identified reliably by a handheld Doppler probe. ${ }^{16}$ Greater knowledge of the interlinking channels between perforators allow for larger more reliable flaps to be raised, as perfusion studies have shown, single perforators of the PTAP and PAP can perfuse flaps approximately $40 \%$ of the lower leg surface area each, between the ankle to knee joint. ${ }^{17}$ In certain circumstances where the perforators are not audible on Doppler, we have used the endoscope to directly visualize the perforators prior to raising the flap. ${ }^{18}$ We used our experience from perforator dissection in free flaps to provide a pedicle dissection as long as possible all the way to the source vessel to allow maximum pedicle freedom.

Most of these perforator flaps will require grafting of the secondary defect. In our series, $49 \%$ of cases required 


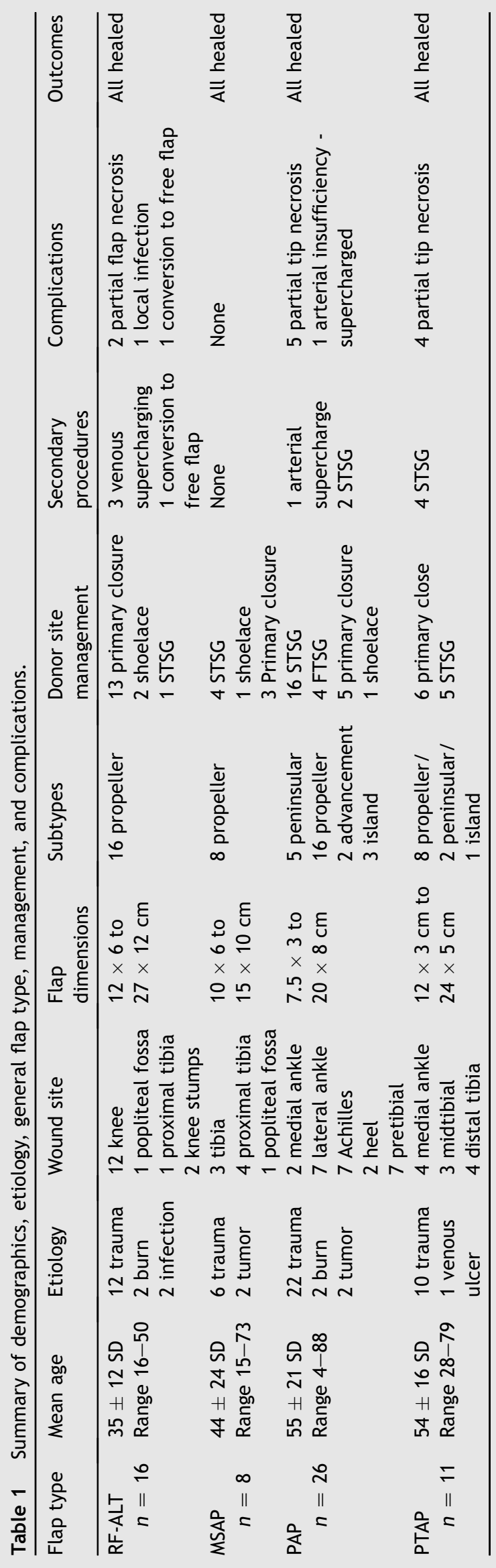

grafting, which is higher than $30.3 \%$ reported in the literature. ${ }^{19}$ This is likely due to our high use of the PAP flap as a propeller flap, as the secondary defect in this area is not particularly pliable. Overall, our complication rate was $28 \%$, with one flap conversion to free, which is similar to the reported literature. ${ }^{19,20}$ Four different PPFs were raised in this study, of which the PAP flap was the most commonly performed 26/61 (43\%) and the RF-ALT flap was the second most common 16/61 (26\%). In the literature, the PTAP flap is by far the more common flap performed, which accounts for $90 \%$ of all flaps used to reconstruct lower limb defects. ${ }^{20}$ The bias of flap use may be a reflection of our center's vast experience with the fibula flap and antero-lateral thigh flap for head and neck reconstruction. ${ }^{21-23}$ Despite many injuries resulting in lateral leg and knee injuries, the perforators remained intact and a reliable source of perfusion for the flaps. In mapping all the defects onto the lower limb, we found that the four flaps could cover $75 \%$ of the lower limb total surface area from the superior patella to the forefoot (Figure 1).

The pedicled RF-ALT flap managed to provide coverage to both lateral knee and proximal tibia. Arterial insufficiency was not seen in our series but has been encountered in other studies. ${ }^{24,25}$ We found venous congestion frequent with the RF-ALT flap (50\%), which we prospectively addressed by venous supercharging. The incidence of venous congestion has been reported as $6 \%$ in other series where the flaps were smaller. ${ }^{24}$ On the basis of this, we advocated venous supercharging using the great saphenous vein if congestion occurs on table. ${ }^{26}$ The need for microsurgery in such cases can be considered a major limitation of this flap.

The MSAP flap provided reliable soft tissue cover for medium-sized defects around the knee. A reported advantage of this flap is that it allows us to preserve the medial gastrocnemius muscle, which would commonly be sacrificed for coverage of defects around the knee. It is arguable how much function this preserves. ${ }^{27}$ This flap has a long pedicle and high pliability, which make it very "efficient." However, the flap has a relatively small volume and the scar can be unsightly. Other options described include $\mathrm{V}-\mathrm{Y}$ perforator flaps around the knee, based on fascial feeders in this region. ${ }^{28}$ We found injuries around the knee and upper leg, such as muscular contusion or degloving to the calf from bumper injuries, would exclude the use of the MSAP flap as intramuscular dissection was hampered by a bruised field, even if the perforator was intact.

The PAP flap was the most used flap in this study. This flap was reliable in all its designs; however, the incidence of transient venous congestion in propeller flaps was high (19\%). The constant septocutaneous perforators arising from the middle to distal third of the leg allowed for raising of flaps well suited for covering for distal half of the lower leg and ankle region. ${ }^{9}$ There was usually at least one reliable dominant perforator that could be used in keeping with reported anatomical studies ${ }^{3}$

We used propeller flaps most frequently. These flaps have high versatility to reach difficult-to-cover areas such as lateral malleolus, Achilles tendon, and dorsum of foot. The secondary defect usually requires skin grafting, which 


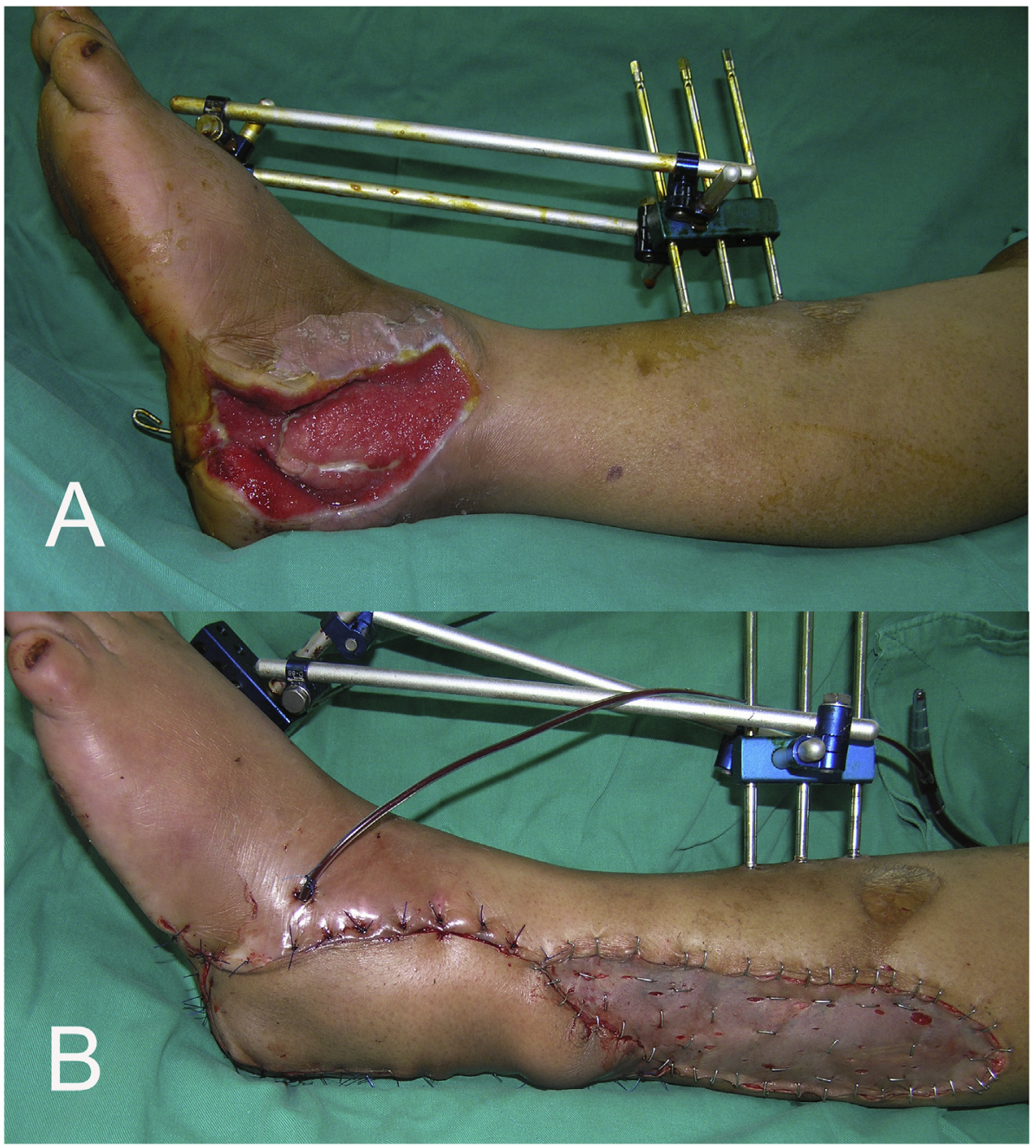

Figure 4 A large lateral ankle fracture dislocation with skin loss (A) requiring a propellered pedicled PAP flap with skin grafting to secondary defect $(B)$.

Table 2 Summary of flap characteristics and efficiency.

\begin{tabular}{|c|c|c|c|c|c|c|c|}
\hline $\begin{array}{l}\text { Pedicled } \\
\text { flap type }\end{array}$ & $\begin{array}{l}\text { Mean defect } \\
\text { size } \mathrm{cm}^{2} \\
\text { (Range) }\end{array}$ & $\begin{array}{l}\text { Mean flap } \\
\text { size } \mathrm{cm}^{2} \\
\text { (Range) }\end{array}$ & $\begin{array}{l}\text { Mean size of } \\
\text { Inset } \mathrm{cm}^{2} \\
\text { (Range) }\end{array}$ & $\begin{array}{l}\text { Mean area } \\
\text { grafted } \mathrm{cm}^{2} \\
\text { (Range) }\end{array}$ & $\begin{array}{l}\text { Mean } \\
\text { rotation } \\
\text { (Range) }\end{array}$ & $\begin{array}{l}\text { Mean } \\
\text { advancement } \\
\text { cm (Range) }\end{array}$ & $\begin{array}{l}\text { Flap Efficiency \% } \\
\text { (Range) }\end{array}$ \\
\hline RF-ALT & $68(21-$ & $117(49$ & 831 & 10.4 & $129(49$ & 19.6 & 00) \\
\hline MSAP & $39.5(18.5-57.5)$ & $56.5(39.8-80.8)$ & $50(28-75.5)$ & $7(0-20)$ & $80(21-125)$ & $7.4(3.5-11.2)$ & $69.9(44.6-94)$ \\
\hline PAP & $19(3.5-48)$ & $65(12-131)$ & $42(8-104)$ & $22.5(0-97)$ & $94(0-170)$ & $1.3(0-7.7)$ & $33.2(8-65)$ \\
\hline PTAP & $20(5-42.5)$ & $68(33-100)$ & 63 (33.5-99.5) & $26(0-55.5)$ & $62(0-167)$ & $2(0-3.7)$ & $31.4(8.5-49.7)$ \\
\hline
\end{tabular}

is a major limitation of this flap. In addition, the flap raised is usually much larger than the defect to provide cover largely due to its short pedicle, and hence less flap efficiency. Nonlinear finite element simulation calculated that a $1.0 \mathrm{~mm}$ diameter and $3.0 \mathrm{~cm}$ pedicle length is required to adequately provide $180^{\circ}$ arc of rotation in propeller design. ${ }^{29}$ Anatomical studies of the PAP flaps support these calculations claiming adequate rotation of vessels $0.8 \mathrm{~mm}$ in diameter with $3.7-5.4 \mathrm{~mm}$ pedicle length. ${ }^{3}$ The PAP flap based on the distal third of the lower leg is our favored choice in traumatic injuries. The perforator is relatively robust and skin paddles in this area can be competent in this area even after previous fibular fractures. ${ }^{30}$

PTAP flaps have the largest diameter perforators and have been extensively used in lower extremity reconstruction, often as propeller flaps. ${ }^{31,32}$ The PTAP was performed in 11 patients for medial-side leg defects. Thirty-six percent of these flaps had tip necrosis requiring secondary skin grafting or second flap cover. Schaverien et al. ${ }^{31}$ reported reliable reconstructions with this flap in a large 


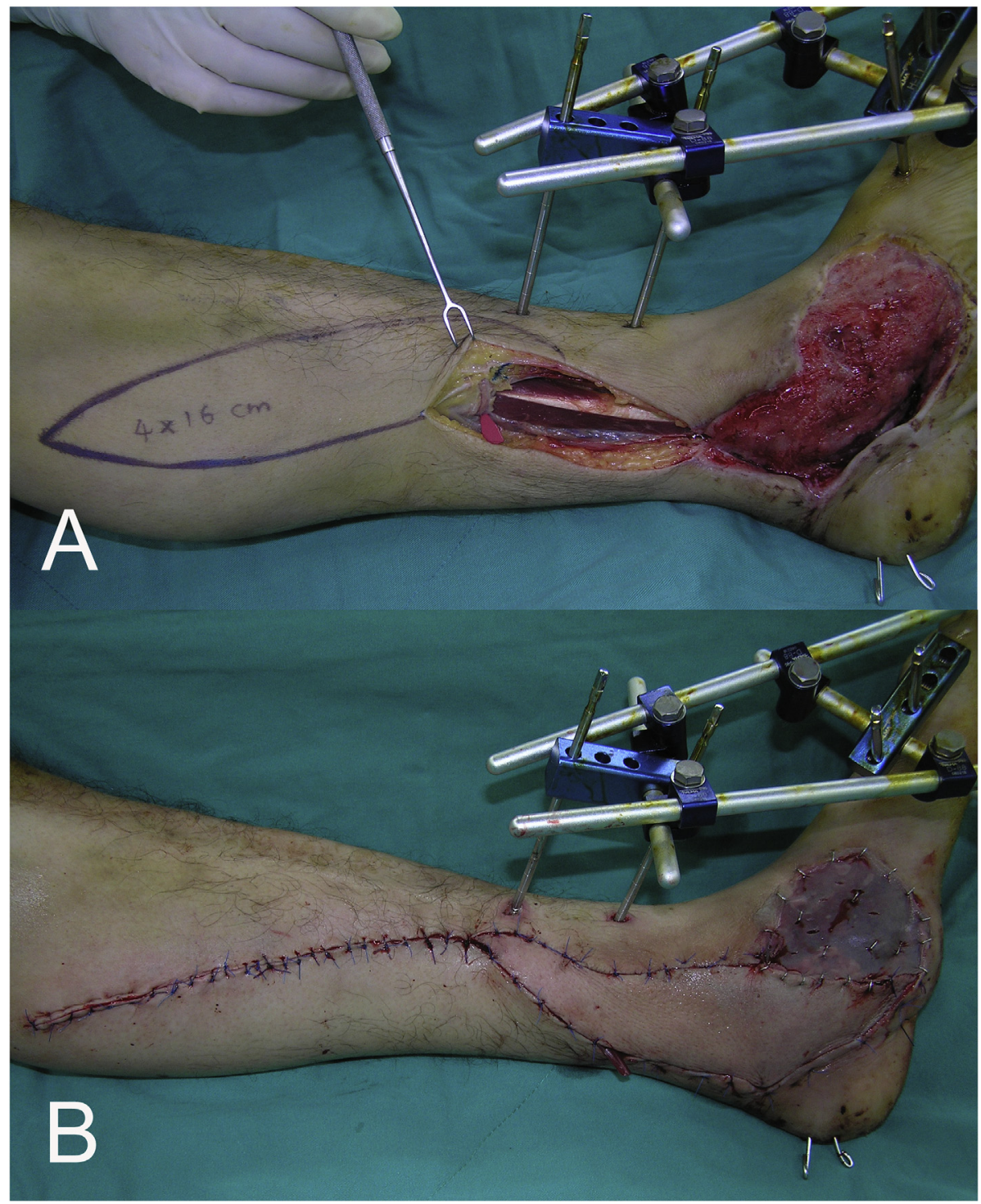

Figure 5 A medial ankle fracture dislocation with skin loss (A) reconstructed with a propellered pedicled PTAP flap (B), which allowed for direct closure of secondary defect.

series with a $8.5 \%$ complete flap failure rate, for which diabetes and occlusive artery disease appeared to influence, and Erdmann et al. reported $7.6 \%$ overall flap failure rate, with a further $10.6 \%$ of flaps suffering from tip necrosis. ${ }^{33}$ Although Robotti et al. expressed high satisfaction with the PTAP flaps, ${ }^{34}$ we found that the PTAP flap are less reliable than the PAP flap in the trauma setting.

In our experience, PTAP flaps provide thin and pliable soft tissue coverage of the medial malleolar region, the anterior shin and Achilles territories ${ }^{35}$ and can provide a reliable alternative for lower leg and ankle defects in situations where PAP flaps may be compromised.

The limitations of this study include the heterogeneity of the defects being reconstructed and the relatively small flap numbers in some groups. There is also a degree of subjectivity in the selection of cases to be managed by PPFs as this decision is based on the surgeon's analysis of risk and suitability. The avoidance of microsurgical anastomosis is one of the benefits of PPFs; however, the need to supercharge four cases in our study shows that on occasion microsurgery is needed to salvage. The RF ALT flap is especially prone and needs to be considered for supercharging routinely.

The techniques used to analyze the flap characteristics in this study is a first attempt at quantifying the relative "efficiency" of a flap and map the area that they can cover. A range of propriety wound assessment software exists and can be used to perform this task; however, Image $\mathrm{J}$ has been validated and is the choice of the scientific community because of its free access and extensive validation in research. ${ }^{36}$ The value of this study would be to use this information to guide the clinical decision-making process of which flap to use for a given defect. Cumulative data acquisition using these measurements and location parameters, together with clinical data may be amenable to the development of algorithms that can predict which flaps 


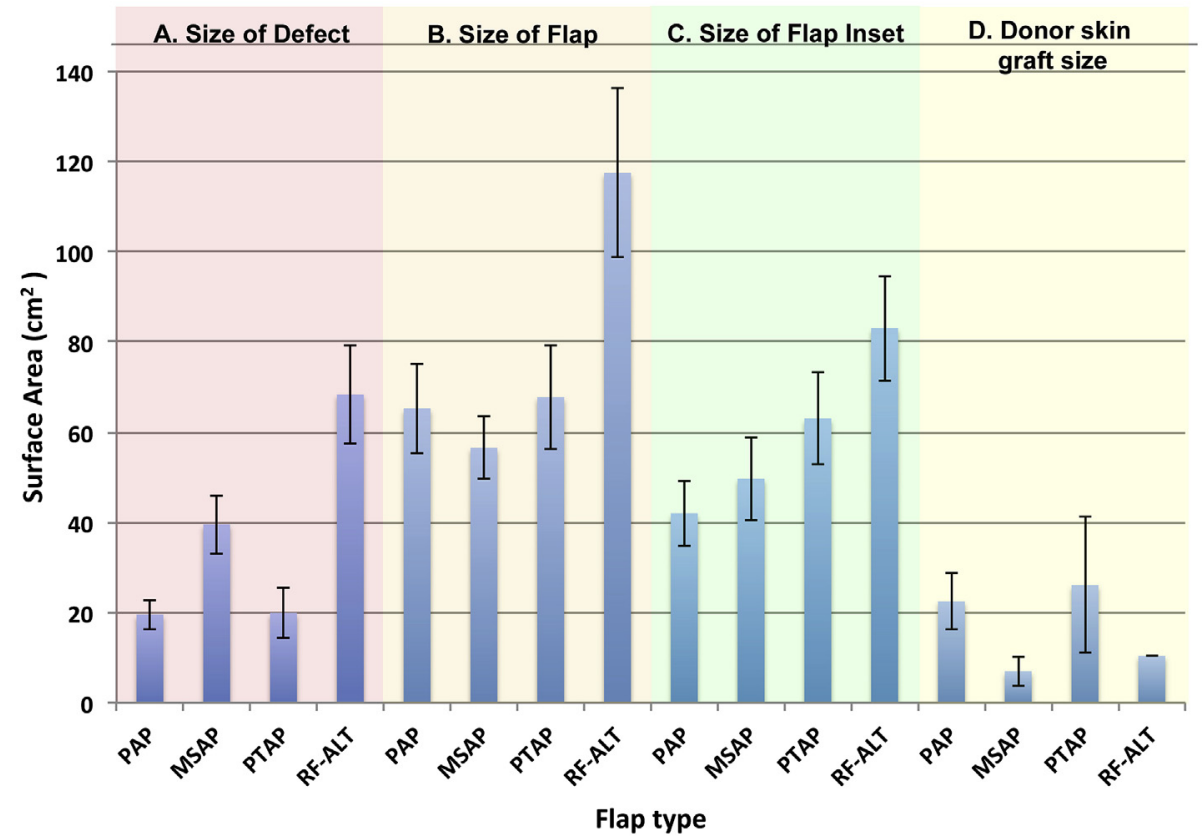

Figure 6 Comparison of mean reconstructive dimensions. A. Size of defect. B. Size of flap raised. C. Size of flap at inset. D. Donor skin graft area. (Error bars denote standard error).

Flap Advancement

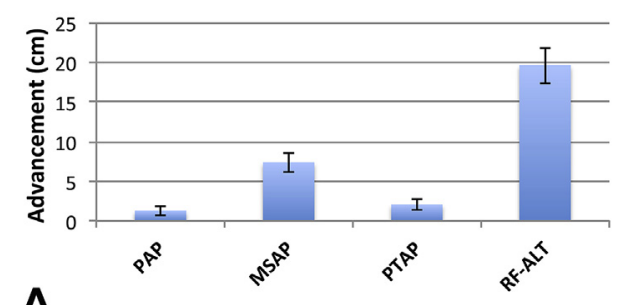

A

Flap type

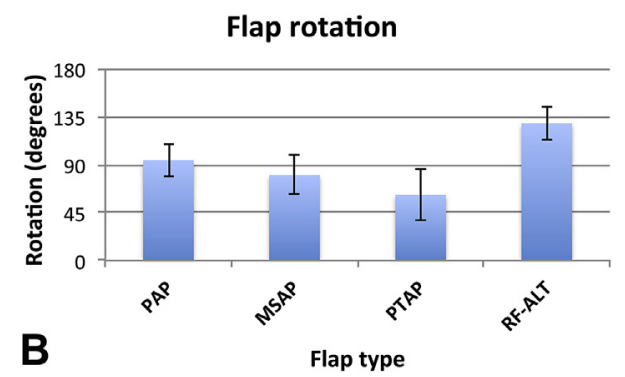

Figure 7 Mean flap mobility. A. Flap advancement. B. Flap rotation (Error bars denote standard error).

are best used at which sites and provide an accurate risk assessment for any given reconstruction when all other patient factors are taken into account. Information gathered in this way aims to be part of "big data" acquisition, which is being used in many areas of health care to describe, predict, and model outcomes. ${ }^{37}$ Threedimensional wound measurement tools are under development, which would provide higher accuracy. ${ }^{38}$ Our future work will aim to develop a more user-friendly application
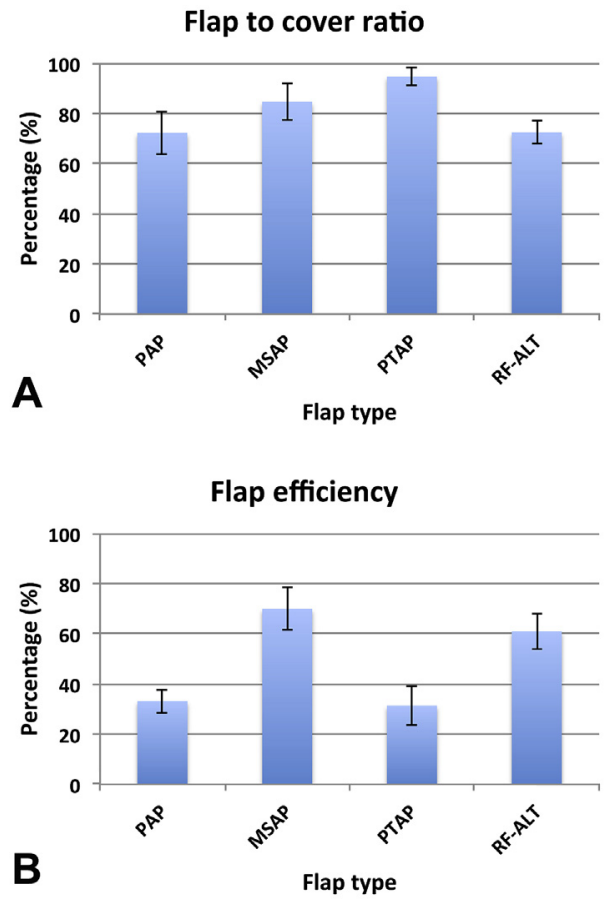

Figure 8 Flap-to-cover ratio and flap efficiency (Error bars denote standard error).

specific for the lower limb to capture clinical data assessing the performance of all flaps.

\section{Financial disclosure statement}

None of the authors has financial interest in any of the products, devices, or drugs mentioned in this manuscript. 


\section{Conflict of interest statement}

None.

\section{Funding}

This study was made feasible by funding from the British Society of Surgery of the Hand (BSSH) and British Association of Plastic Reconstructive and Aesthetic Surgeons (BAPRAS) travel bursaries.

\section{Appendix A. Supplementary data}

Supplementary data related to this article can be found at http://dx.doi.org/10.1016/j.bjps.2016.09.028.

\section{References}

1. Hong JP, Kim EK. Sole reconstruction using anterolateral thigh perforator free flaps. Plast Reconstr Surg 2007;119:186-93.

2. Hui-Chou HG, Sulek J, Bluebond-Langner R, Rodriguez ED. Secondary refinements of free perforator flaps for lower extremity reconstruction. Plast Reconstr Surg 2011;127: 248-57.

3. Schaverien M, Saint-Cyr M. Perforators of the lower leg: analysis of perforator locations and clinical application for pedicled perforator flaps. Plast Reconstr Surg 2008;122:161-70.

4. Blondeel N, Boeckx WD, Vanderstraeten GG, et al. The fate of the oblique abdominal muscles after free TRAM flap surgery. $\mathrm{Br}$ J Plast Surg 1997;50:315-21.

5. Salmi A, Tuominen R, Tukiainen E, Asko-Seljavaara S. Morbidity of donor and recipient sites after free flap surgery. A prospective study. Scand J Plast Reconstr Surg Hand Surg 1995;29: 337-41.

6. Demirkan F, Chen HC, Wei FC, et al. The versatile anterolateral thigh flap: a musculocutaneous flap in disguise in head and neck reconstruction. Br J Plast Surg 2000;53:30-6.

7. Saint-Cyr M, Schaverien M, Arbique G, et al. Three- and fourdimensional computed tomographic angiography and venography for the investigation of the vascular anatomy and perfusion of perforator flaps. Plast Reconstr Surg 2008;121: 772-80.

8. Mateev MA, Kuokkanen HO. Reconstruction of soft tissue defects in the extremities with a pedicled perforator flap: series of 25 patients. J Plast Surg Hand Surg 2012;46:32-6.

9. Lu TC, Lin CH, Lin CH, et al. Versatility of the pedicled peroneal artery perforator flaps for soft-tissue coverage of the lower leg and foot defects. J Plast Reconstr Aesthet Surg 2011; 64:386-93.

10. Lee BT, Lin SJ, Bar-Meir ED, Borud LJ, Upton J. Pedicled perforator flaps: a new principle in reconstructive surgery. Plast Reconstr Surg 2010;125:201-8.

11. Saint-Cyr M, Schaverien MV, Rohrich RJ. Perforator flaps: history, controversies, physiology, anatomy, and use in reconstruction. Plast Reconstr Surg 2009;123:132e-45e.

12. Girish V, Vijayalakshmi A. Affordable image analysis using $\mathrm{NIH}$ Image/ImageJ. Indian J Cancer 2004;41:47.

13. Barlow JO. The tissue efficiency of common reconstructive design and modification. Dermatol Surg 2009;35:613-28.

14. Bekara F, Herlin C, Somda S, et al. Free versus perforatorpedicled propeller flaps in lower extremity reconstruction: what is the safest coverage? A Meta-analysis. Microsurgery 2016 Mar 28. http://dx.doi.org/10.1002/micr.30047 [Epub ahead of print].
15. Engel $\mathrm{H}$, Lin $\mathrm{CH}$, Wei FC. Role of microsurgery in lower extremity reconstruction. Plast Reconstr Surg 2011; 127(Suppl. 1):228S-38S.

16. Celik N, Wei FC, Lin CH, et al. Technique and strategy in anterolateral thigh perforator flap surgery, based on an analysis of 15 complete and partial failures in 439 cases. Plast Reconstr Surg 2002;109:2211-6. discussion 17-8.

17. Sur YJ, Morsy M, Mohan AT, et al. Three-dimensional computed tomographic angiographic study of the inter-perforator flow of the lower leg. Plast Reconstr Surg 2016;137:1615-28.

18. Katsuragi-Tomioka Y, Nakagawa M, Yamamoto Y, Kayano S, Matsui T. Endoscope-assisted perforator flap harvest. Plast Reconstr Surg 2012;129:597e-9e.

19. Bekara F, Herlin C, Mojallal A, et al. A systematic review and meta-analysis of perforator-pedicled propeller flaps in lower extremity defects: identification of risk factors for complications. Plast Reconstr Surg 2016;137:314-31.

20. Gir P, Cheng A, Oni G, Mojallal A, Saint-Cyr M. Pedicledperforator (propeller) flaps in lower extremity defects: a systematic review. J Reconstr Microsurg 2012;28:595-601.

21. Wei FC, Jain V, Celik N, et al. Have we found an ideal softtissue flap? An experience with 672 anterolateral thigh flaps. Plast Reconstr Surg 2002;109:2219-26. discussion 27-30.

22. Wei FC, Celik N, Chen HC, Cheng MH, Huang WC. Combined anterolateral thigh flap and vascularized fibula osteoseptocutaneous flap in reconstruction of extensive composite mandibular defects. Plast Reconstr Surg 2002;109:45-52.

23. Santamaria E, Wei FC, Chen HC. Fibula osteoseptocutaneous flap for reconstruction of osteoradionecrosis of the mandible. Plast Reconstr Surg 1998;101:921-9.

24. Demirseren ME, Efendioglu K, Demiralp CO, Kilicarslan K, Akkaya H. Clinical experience with a reverse-flow anterolateral thigh perforator flap for the reconstruction of softtissue defects of the knee and proximal lower leg. J Plast Reconstr Aesthet Surg 2011;64:1613-20.

25. Yildirim S, Gideroglu K, Akoz T. Anterolateral thigh flap: ideal free flap choice for lower extremity soft-tissue reconstruction. J Reconstr Microsurg 2003;19:225-33.

26. Lin $\mathrm{CH}$, Hsu CC, Lin CH, Chen YC, Wei FC. Antegrade venous drainage in a reverse-flow anterolateral thigh flap. Plast Reconstr Surg 2009;124:273e-4e.

27. Daigeler A, Drucke D, Tatar K, et al. The pedicled gastrocnemius muscle flap: a review of 218 cases. Plast Reconstr Surg 2009;123:250-7.

28. Niranjan NS, Price RD, Govilkar P. Fascial feeder and perforator-based $\mathrm{V}$-Y advancement flaps in the reconstruction of lower limb defects. Br J Plast Surg 2000;53:679-89.

29. Wong $\mathrm{CH}$, Cui F, Tan BK, et al. Nonlinear finite element simulations to elucidate the determinants of perforator patency in propeller flaps. Ann Plast Surg 2007;59:672-8.

30. Chan RC, Wei FC, Wong JK, Wu CM. Is distal fibular fracture an absolute contraindication to free fibular flap harvesting? A review of evidence in the literature and illustration by a successful case. Microsurgery 2015;35:60-3.

31. Schaverien MV, Hamilton SA, Fairburn N, Rao P, Quaba AA. Lower limb reconstruction using the islanded posterior tibial artery perforator flap. Plast Reconstr Surg 2010;125: 1735-43.

32. Niranjan NS. Posterior tibial artery perforator flap. In: Wei FC, Mardini S, editors. Flaps and reconstructive surgery. China: Elvsevier; 2009. p. 600-16.

33. Erdmann MW, Court-Brown CM, Quaba AA. A five year review of islanded distally based fasciocutaneous flaps on the lower limb. Br J Plast Surg 1997;50:421-7.

34. Robotti E, Carminati M, Bonfirraro PP, et al. "On demand" posterior tibial artery perforator flaps: a versatile surgical procedure for reconstruction of soft tissue defects of the leg after tumor excision. Ann Plast Surg 2010;64:202-9. 
35. Mopuri N, Karri V, Patel N, Niranjan NS. Reconstruction of soft tissue defects in the Achilles tendon region with perforatorbased fasciocutaneous flaps. Eur J Plast Surg 2013;36:701-6.

36. Foltynski P, Ladyzynski P, Ciechanowska A, et al. Wound area measurement with digital planimetry: improved accuracy and precision with calibration based on 2 rulers. PLoS One 2015; 10 : e0134622.
37. Chang H, Choi M. Big data and healthcare: building an augmented world. Healthc Inf Res 2016;22:153-5.

38. Bills JD, Berriman SJ, Noble DL, Lavery LA, Davis KE. Pilot study to evaluate a novel three-dimensional wound measurement device. Int Wound J 2015 Nov 11. http: //dx.doi.org/10.1111/iwj.12534 [Epub ahead of print]. 